ISSN = 1980-993X - doi:10.4136/1980-993X
www.agro.unitau.br/ambi-agua
E-mail: ambi-agua@agro.unitau.br
Tel.: (12) 3625-4116

\title{
Caracterização de metais em precipitação atmosférica em uma Floresta Ombrófila Mista (doi:10.4136/ambi-agua.98)
}

\section{Andressa Beló; Sueli Pércio Quináia; Nayara Kaminski de Oliveira; Luciano Farinha Watzlawick}

\author{
Universidade Estadual do Centro-Oeste - UNICENTRO \\ E-mail: andressab@sanepar.com.br; spquinaia@unicentro.br; \\ naykaminski@hotmail.com; farinha@unicentro.br
}

\section{RESUMO}

Este trabalho aborda alguns aspectos relativos ao estudo da precipitação atmosférica, focalizando a avaliação do teor de metais, tanto na fração dissolvida como no material particulado, de uma floresta na região do município de Guarapuava, PR. Amostras de precipitação atmosférica foram coletadas usando coletores de precipitação total localizados no interior e fora da floresta. O período das coletas foi de 12 meses e os parâmetros analisados foram $\mathrm{pH}$, condutividade, $\mathrm{Al}, \mathrm{Cd}, \mathrm{Cr}, \mathrm{Fe}, \mathrm{Mn}, \mathrm{Ni}$ e $\mathrm{Pb}$. A ACP (Análise de Componentes Principais) foi realizada para melhor compreensão dos dados obtidos e indicou que cada evento chuvoso foi responsável pela discriminação das amostras provenientes de cada coleta no interior da floresta e fora desta. Os resultados de $\mathrm{pH}$ revelaram a ocorrência de precipitação levemente ácida. Alguns metais apresentaram valores acima do estabelecido pelo CONAMA, Resolução $n^{\circ}$ 357. Metais tóxicos de origem antropogênica foram encontrados demonstrando que os fenômenos climáticos contribuíram para a dispersão da poluição provenientes do meio urbano.

Palavras-chave: precipitação; material particulado; metais; floresta; ACP.

\section{Characterization of Metals in atmospheric precipitation in an Ombrophyllous Mixed Forest}

\section{ABSTRACT}

This work addresses some aspects related to the study of metals content evaluation from atmospheric precipitation considering both the fraction dissolved and the particulate matter in forest of Guarapuava region, PR. Samples of atmospheric precipitation were collected using collectors of total precipitation located inside and outside of a forest patch. Samples were collected during 12 months and the analyzed parameters were $\mathrm{pH}$, conductivity, $\mathrm{Al}, \mathrm{Cd}, \mathrm{Cr}$, $\mathrm{Fe}, \mathrm{Mn}, \mathrm{Ni}$ and $\mathrm{Pb}$. The PCA (Principal Components Analysis) was performed and indicated that each rain event was responsible for the discrimination of samples from each sample collected within and outside the forest. Results of $\mathrm{pH}$ measurements revealed the occurrence of slightly acidic precipitation. Some metal had values above CONAMA $n^{\circ} 357$ acceptance values. Toxic metals of anthropogenic origin were found demonstrating that weather phenomena contributed to the dispersion of pollution from urban areas.

Keywords: precipitation; particulate matter; metals; forest; PCA. 
BELÓ, A.; QUINÁIA, S. P.; OLIVEIRA, N. K.; WATZLAWICK, L. F. Caracterização de metais em precipitação atmosférica em uma Floresta Ombrófila Mista. Ambi-Agua, Taubaté, v. 4, n. 2, p. 200-211, 2009. (doi:10.4136/ambi-agua.98)

\section{INTRODUÇÃO}

O desenvolvimento industrial e urbano tem originado um aumento crescente da emissão de poluentes atmosféricos. O acréscimo das concentrações desses poluentes e a deposição dos mesmos nos solos e nos ambientes aquáticos são fatores responsáveis por danos à saúde humana, pois causam desequilíbrios nos ecossistemas (Queiroz et al., 2007). A deposição desses poluentes ocorre pelo ciclo hidrológico. Durante as etapas do ciclo hidrológico, materiais particulados como a poeira, por exemplo, se acumulam na atmosfera e são depositados juntamente com a precipitação. Dessa forma, a água incorpora a maioria das substâncias presentes na atmosfera, sejam de origem natural ou resíduos da atividade humana (Silva, 2006; Loureiro, 2005). Assim, a composição da chuva pode variar de um lugar para outro pela ação de vários fatores, como, por exemplo, o tipo de ecossistema presente e alguns parâmetros meteorológicos, o clima e o regime de ventos.

$\mathrm{Na}$ natureza, a água da chuva não é pura devido, principalmente, a presença de sais de origem marinha e dos gases que compõem a atmosfera. Esses elementos podem ser dissolvidos na água ou reagir com ela. $\mathrm{O}$ gás carbônico é um dos principais responsáveis pelo caráter ácido da chuva. No entanto, outros gases, como os óxidos de nitrogênio ou de enxofre, também reagem com a água, formando substâncias ácidas (Baird, 2002).

Um dos problemas ambientais mais graves que muitas regiões do mundo vêm enfrentando é a chuva ácida. Esse termo genérico abrange vários fenômenos, como a neblina ácida e a neve ácida, todos relacionados a precipitações substanciais de ácido. Do ponto de vista da análise química, a chuva ácida corresponde àquela em que o $\mathrm{pH}$ se apresenta inferior a 5,65 (Baird, 2002 e Jesus, 1996). O ácido que cai das nuvens sobre qualquer região do planeta é responsável pela destruição de metais, de monumentos públicos, mortes das plantas, diminuição da produção agrícola, acidificação de rios e lagos, resultando na morte de sua flora e fauna, afetando à saúde humana (Loureiro, 2005).

As partículas que se encontram suspensas no ar são denominadas material particulado. Algumas dessas partículas podem ser grandes, escuras e, outras, são tão pequenas que somente podem ser vistas através de um microscópio (Queiroz et al., 2007). As menores partículas suspensas atingem cerca de $0,002 \mu \mathrm{m}$, sendo o limite superior correspondente a cerca de $100 \mu \mathrm{m}$ de diâmetro. Quando as gotículas de água presentes na atmosfera crescem para constituir partículas maiores do que essa, elas formam gotas de chuva e precipitam-se em direção ao solo rapidamente (Baird, 2002).

A fonte de origem do material particulado pode ser natural ou artificial. Como fontes naturais podem ser citados o spray marinho, pólen, poeiras e vulcões ou outras formas de erupção geotérmica. Como fontes artificiais têm-se motores de veículos, caldeiras industriais, queima da vegetação e fumaça de cigarro. Dependendo dos tipos de fontes existentes e de suas interações com outros componentes presentes na atmosfera, as composições químicas, bem como os impactos causados à saúde humana,podem ser diferentes (Queiroz et al., 2007).

Os metais diferem de outros agentes tóxicos porque não são sintetizados nem destruídos pelo homem. A atividade industrial diminui significativamente a permanência desses metais nos minérios, bem como a produção de novos compostos, além de alterar a distribuição desses elementos no planeta (Pimentel et al., 2006). A presença de metais muitas vezes está associada à localização geográfica, seja na água ou no solo (Lee, 1996). Todas as formas de vida são afetadas pela presença de metais dependendo da dose e da forma química. Muitos metais são essenciais para o crescimento de todos os tipos de organismos, desde as bactérias até mesmo o ser humano, mas eles são requeridos em baixas concentrações e podem danificar sistemas biológicos (Larini, 1997 e Jardim et al., 2008).

Em química, o termo metal pesado refere-se a uma classe de elementos químicos, muitos dos quais tóxicos para os seres humanos. Os metais diferenciam-se de outros compostos 
tóxicos por serem absolutamente não-degradáveis, de maneira que podem acumular-se nos componentes do ambiente onde manisfestam sua toxicidade. Os locais de fixação final dos metais são os solos e sedimentos (Mariani, 2006).

Embora pensemos nos metais pesados como poluentes da água e como contaminantes de nossos alimentos, eles são em sua maioria transportados de um lugar para outro por via aérea, seja como gases ou como espécies adsorvidas sobre ou absorvidas em material particulado em suspensão (Loureiro, 2005), por isso a atmosfera é um compartimento de suma importância devido ao transporte dessas substâncias, sendo a deposição atmosférica considerada fonte significativa de metais tóxicos para os ecossistemas naturais (Fontenele e Pedrotti, 2009).

O objetivo desse trabalho foi avaliar a composição química de amostras de precipitação, por meio de medidas de $\mathrm{pH}$, condutividade e teor de metais, tanto na fração dissolvida como no material particulado atmosférico coletado junto à precipitação em ambiente de Floresta Ombrófila Mista. Esse tipo de ecossistema florestal, também conhecido como Floresta de Araucária é um ecossistema com chuva durante o ano todo, normalmente em altitudes elevadas e encontra-se distribuída nos estados do Rio Grande do Sul, Santa Catarina, Paraná, São Paulo e Minas Gerais (Sonego et al., 2007).

\section{MATERIAL E MÉTODOS}

\subsection{Pontos de coleta e preparo das amostras}

A definição dos pontos de amostragem foi feita aleatoriamente no interior de um fragmento da Floresta Ombrófila Mista - FOM - (IBGE, 1992) - que possui aproximadamente $5.000 \mathrm{~m} 2$ ) e fora desta. Segundo Klein (1960), a FOM apresenta ocorrência preferencial nos estados do Sul do Brasil, sendo inconfundível fisionomicamente devido à presença de Araucaria angustifolia como espécie típica e caracterizadora desse bioma. A Figura 1 representa a localização da cidade de Guarapuava-PR e a aérea do fragmento da Floresta Ombrófila Mista.

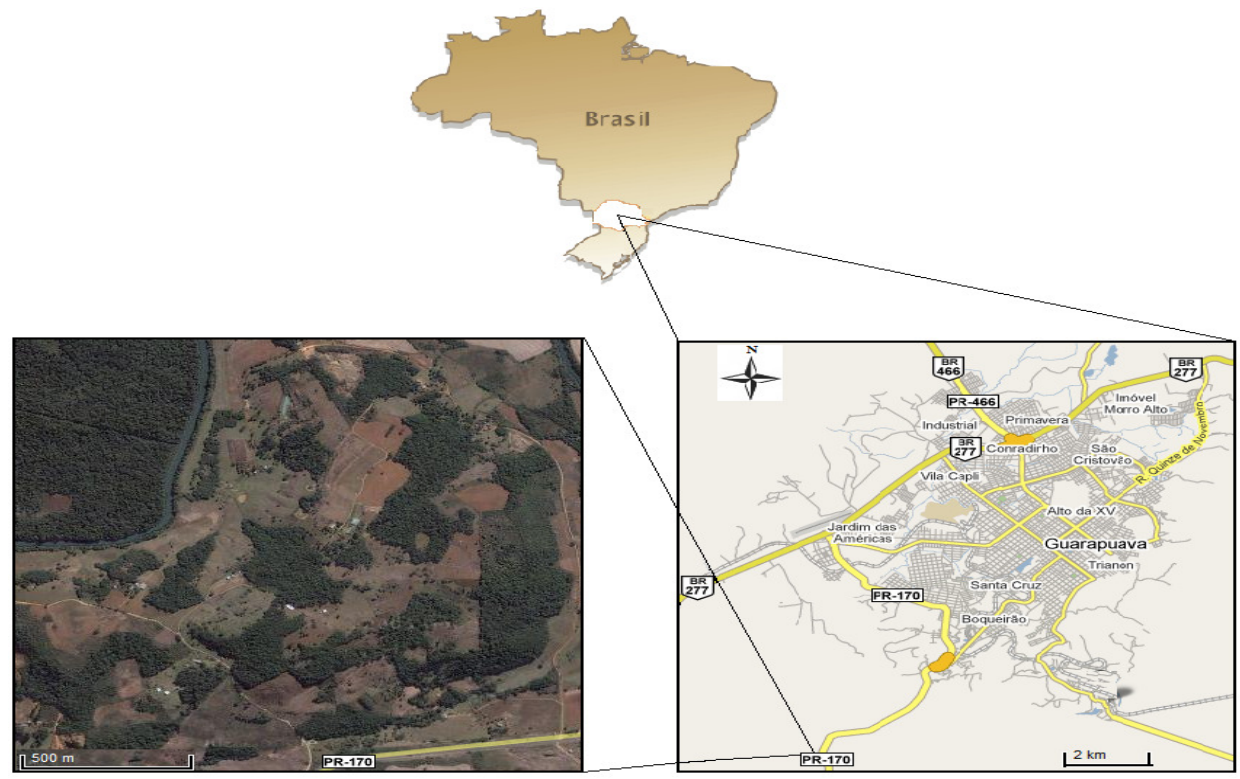

Figura 1. Localização do município de Guarapuava - PR com a imagem de um fragmento da Floresta Ombrófila Mista.

Fonte: Google, 2009.

Ao todo, foram distribuídos 6 coletores dentro da floresta com uma distância média de aproximadamente $20 \mathrm{~m}$, e 4 coletores fora dela, localizados em uma área de cultivo agrícola a uma distância de $30 \mathrm{~m}$ da floresta. Para fins comparativos, foram amostrados 4 pontos 
BELÓ, A.; QUINÁIA, S. P.; OLIVEIRA, N. K.; WATZLAWICK, L. F. Caracterização de metais em precipitação atmosférica em uma Floresta Ombrófila Mista. Ambi-Agua, Taubaté, v. 4, n. 2, p. 200-211, 2009. (doi:10.4136/ambi-agua.98)

pertencentes a um ambiente aquático localizado no centro da floresta (nascente, córrego e tanque).

Foram utilizados coletores de precipitação total (coletor aberto permanentemente, durante eventos chuvosos e períodos secos) para a coleta dos componentes atmosféricos da deposição úmida (chuva) e seca (gases dispersos e partículas em suspensão), constituído de um funil de polietileno, com $21,5 \mathrm{~cm}$ de diâmetro, acoplado a um frasco coletor de $5 \mathrm{~L}$ do mesmo material por uma mangueira de $50 \mathrm{~cm}$, ambos fixados a uma estrutura de madeira de $1,00 \mathrm{~m}$, ficando em contado com o solo. O funil foi recoberto com tela de nylon para impedir a contaminação das amostras por agentes externos, tais como folhas e insetos (Figura 2) (Migliavacca et al., 2005 e Campos et al., 1998).

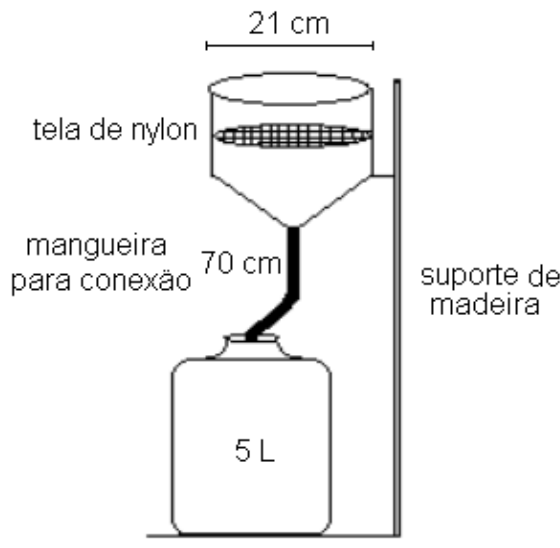

Figura 2. Coletor de precipitação total.

A amostragem foi realizada no período de um ano, e as amostras foram coletadas aproximadamente a cada 15 dias. Existiram eventos de estiagem em que as amostras foram recolhidas em um intervalo de até 30 dias.

Após as coletas, as amostras foram filtradas com auxílio de uma bomba de vácuo e membrana de acetato de celulose $(0,45 \mu \mathrm{m})$, previamente secas e pesadas a $60^{\circ} \mathrm{C}$ antes do uso.

$\mathrm{O}$ material obtido após a filtração foi seco em estufa a $60^{\circ} \mathrm{C}$ por 1 hora e resfriado em dessecador até peso constante deste. Isso permitiu obter a quantidade de material particulado por amostra. Após, a membrana contendo o particulado foi digerida com $10 \mathrm{~mL}$ de uma mistura de ácidos ácido nítrico e ácido clorídrico concentrados (3:1) em chapa de aquecimento com temperatura de aproximadamente $150^{\circ} \mathrm{C}$. A mistura resultante foi avolumada com água deionizada em balões volumétricos. O Fluxograma 1 apresenta o procedimento de preparação das amostras de precipitação (fases dissolvida e particulada).

Os extratos obtidos após a filtração foram transferidas para frascos de polietileno (cap. $100 \mathrm{~mL}$ ) acidificados com ácido nítrico até $\mathrm{pH}$ de 1,5 e estocados em refrigerador $\left(4^{\circ} \mathrm{C}\right)$ por um período máximo de 24 horas. 
BELÓ, A.; QUINÁIA, S. P.; OLIVEIRA, N. K.; WATZLAWICK, L. F. Caracterização de metais em precipitação atmosférica em uma Floresta Ombrófila Mista. Ambi-Agua, Taubaté, v. 4, n. 2, p. 200-211, 2009. (doi:10.4136/ambi-agua.98)

Fluxograma 1. Procedimento analítico utilizado para

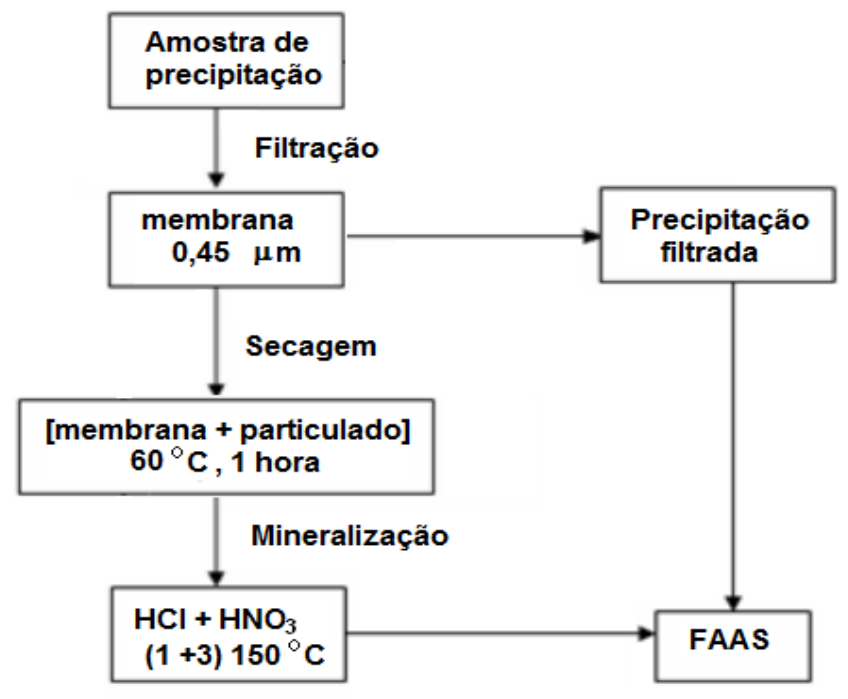

o preparo das amostras.

\subsection{Instrumentação e reagentes}

Toda vidraria utilizada nos experimentos e frascos de estocagem de amostras foram deixados de molho em banho ácido nítrico $10 \%$ v/v por um período de $24 \mathrm{~h}$, e enxaguados com água deionizada Tipo I (Human-900).

Medidas de $\mathrm{pH}$ e condutividade foram realizadas em amostras não filtradas. Foi utilizado pHmetro (C 3535, precisão $\pm 0,01$ ), calibrado com soluções tampão de $\mathrm{pH} 4,01$ e 7,00, e condutivímetro (C 3535, precisão $\pm 0,01$ ) calibrado com solução padrão $1,0 \times 10^{-2} \mathrm{~mol} \mathrm{~L}^{-1} \mathrm{de}$ $\mathrm{KCl}$. Na filtragem das amostram para retirada do material particulado foi utilizado um Holder e bomba a vácuo. Os reagentes utilizados na digestão foram de grau analítico.

Os metais $\mathrm{Al}, \mathrm{Cd}, \mathrm{Cr}, \mathrm{Fe}, \mathrm{Mn}, \mathrm{Ni}$ e $\mathrm{Pb}$ foram quantificados em Espectrômetro de Absorção Atômica em Chama - FAAS (Varian, SpectraAAS-20). Foram utilizadas soluções padrão de $1000 \mathrm{mg} . \mathrm{L}^{-1}$ para cada metal, o branco utilizado foi água deionizada. Todas as amostras foram medidas em triplicata. A Tabela 1 apresenta os parâmetros experimentais utilizados para determinação dos metais em FAAS.

Tabela 1. Parâmetros experimentais de medida dos metais por FAAS.

\begin{tabular}{ccccc}
\hline Metais & $\boldsymbol{\lambda}(\mathbf{n m})$ & I lâmpada $(\mathbf{m A})$ & Fenda (nm) & Chama \\
\hline $\mathrm{Al}$ & 309,3 & 10 & 0,5 & $\mathrm{~N}_{2} \mathrm{O} / \mathrm{C}_{2} \mathrm{H}_{2}$ \\
$\mathrm{Cd}$ & 228,8 & 4 & 0,5 & $\mathrm{Ar} / \mathrm{C}_{2} \mathrm{H}_{2}$ \\
$\mathrm{Cr}$ & 357,9 & 7 & 0,2 & $\mathrm{Ar} / \mathrm{C}_{2} \mathrm{H}_{2}$ \\
$\mathrm{Fe}$ & 248,3 & 5 & 0,2 & $\mathrm{Ar} / \mathrm{C}_{2} \mathrm{H}_{2}$ \\
$\mathrm{Mn}$ & 279,5 & 5 & 0,2 & $\mathrm{Ar} / \mathrm{C}_{2} \mathrm{H}_{2}$ \\
$\mathrm{Ni}$ & 232,0 & 4 & 0,2 & $\mathrm{Ar} / \mathrm{C}_{2} \mathrm{H}_{2}$ \\
$\mathrm{~Pb}$ & 217,0 & 5 & 1,0 & $\mathrm{Ar} / \mathrm{C}_{2} \mathrm{H}_{2}$ \\
\hline
\end{tabular}

\section{RESULTADOS E DISCUSSÃO}

Para uma correta avaliação e comparação dos resultados obtidos é preciso levar em consideração que cada período chuvoso é único, sendo caracterizado por três variáveis: o intervalo de tempo entre as precipitações atmosféricas; a duração e sua intensidade (Prestes et al., 2006). 
BELÓ, A.; QUINÁIA, S. P.; OLIVEIRA, N. K.; WATZLAWICK, L. F. Caracterização de metais em precipitação atmosférica em uma Floresta Ombrófila Mista. Ambi-Agua, Taubaté, v. 4, n. 2, p. 200-211, 2009. (doi:10.4136/ambi-agua.98)

No início do estudo, a amostragem era constituída de 14 pontos, mas devido à similaridade das amostras entre pontos amostrados, a partir da $9^{a}$ coleta os pontos de coleta foram reduzidos a 5: 2 pontos localizados dentro da floresta, 1 ponto na área de cultivo agrícola e 2 pontos na mina (nascente e tanque).

A Tabela 2 apresenta os resultados obtidos com as análises das amostras filtradas. Devido ao grande número de dados, foram apresentados valores máximos e mínimos de cada parâmetro medido.

Tabela 2. Valores mínimos e máximos de $\mathrm{pH}$, condutividade e metais encontrados em amostras de águas de nascente $(\mathrm{M})$, precipitação dentro da floresta $(\mathrm{D})$ e precipitação fora da floresta (F) na fração dissolvida.

\begin{tabular}{cccc}
\hline \multicolumn{4}{c}{ Amostras filtradas } \\
\hline Parâmetros & M & D & F \\
\hline $\mathrm{pH}$ & $5,02-6,73$ & $5,58-8,65$ & $3,92-6,67$ \\
$\mathrm{Condut.}(\mu \mathrm{S})$ & $17,70-32,30$ & $13,60-91,30$ & $4,40-24,40$ \\
$\mathrm{Al}(\mathrm{mg} / \mathrm{L})$ & $\mathrm{LD}-25,42$ & $\mathrm{LD}-31,29$ & $\mathrm{LD}-34,21$ \\
$\mathrm{Cd}(\mathrm{mg} / \mathrm{L})$ & $\mathrm{LD}$ & $\mathrm{LD}$ & $\mathrm{LD}$ \\
$\mathrm{Cr}(\mathrm{mg} / \mathrm{L})$ & $\mathrm{LD}-0,02$ & $\mathrm{LD}-0,03$ & $\mathrm{LD}$ \\
$\mathrm{Fe}(\mathrm{mg} / \mathrm{L})$ & $\mathrm{LD}-1,66$ & $\mathrm{LD}-0,38$ & $\mathrm{LD}-0,40$ \\
$\mathrm{Mn}(\mathrm{mg} / \mathrm{L})$ & $\mathrm{LD}-0,73$ & $\mathrm{LD}-0,62$ & $\mathrm{LD}-0,73$ \\
$\mathrm{Ni}(\mathrm{mg} / \mathrm{L})$ & $\mathrm{LD}-0,40$ & $\mathrm{LD}-0,15$ & $\mathrm{LD}-0,16$ \\
$\mathrm{~Pb}(\mathrm{mg} / \mathrm{L})$ & $\mathrm{LD}-0,23$ & $\mathrm{LD}-0,30$ & $\mathrm{LD}-0,30$ \\
\hline
\end{tabular}

$\mathrm{LD}=$ Limite de detecção.

Os valores de $\mathrm{pH}$ indicaram a existência de precipitação ácida, sendo verificado maior acidez nos pontos coletados fora da floresta $(\mathrm{F})$ atingindo mínimos de $\mathrm{pH}=3,92$, enquanto que valores superiores de $\mathrm{pH}$ foram verificados nos coletores do interior da floresta (D). Essa diferença de $\mathrm{pH}$ ocorre devido à influência da deposição seca pelo acúmulo de material particulado no sistema coletor e nas árvores, pois quando a água da chuva entra em contato com o dossel da floresta, tem suas características físico-químicas alteradas pela lixiviação de metabólitos dos tecidos das folhas, troncos e ramos e também pela lavagem de partículas provenientes da deposição seca que acumulam após o período de estiagem (Souza et al., 2007). As medidas de $\mathrm{pH}$ e condutividade para as amostras de água coletadas na nascente (M) indicaram valores intermediários em relação aos pontos $\mathrm{D}$ e $\mathrm{F}$ devido à diluição que ocorre com os íons presentes na precipitação atmosférica ao se depositarem no ambiente aquático. Os valores de $\mathrm{pH}$ aumentam de acordo com o crescimento da condutividade, ou seja, ocorreu um aumento na concentração de íons dissolvidos nas amostras. A Condutividade variou de 13,60 a $91,30 \mu \mathrm{S}$ para as amostras $\mathrm{D}$ e de 4,40 a $24,40 \mu \mathrm{S}$ para as amostras $\mathrm{F}$, portanto indicando a menor acidez nas amostras coletadas no interior da floresta.

Foram determinados valores elevados de $\mathrm{Al}, \mathrm{Mn}, \mathrm{Ni}$, e $\mathrm{Pb}$ na fração dissolvida em várias amostras, algumas acima do estabelecido pelo CONAMA $n^{\circ} 357$. Ni e $\mathrm{Pb}$ são de origem antropogênica e, provavelmente, provenientes da emissão urbana $(5 \mathrm{~km}$ de distância da floresta em estudo). Migliavacca et al. (2005) determinaram valores de $\mathrm{Ni}, \mathrm{Fe}$ e $\mathrm{Mn}$ em amostras de precipitação coletadas na região de Candiota-RS superiores em relação a este trabalho, no entanto menor valor para o Al. A Tabela 3 apresenta os teores de metais encontrados no material particulado presente nas águas de precipitação. Teores elevados de $\mathrm{Al}, \mathrm{Mn}, \mathrm{Ni}, \mathrm{Pb}$ e Fe foram observados nas amostras. A Tabela 4 apresenta os limites máximos permitidos para metais presentes em águas classe 1 (águas destinadas ao abastecimento doméstico, sem tratamento prévio ou com simples desinfecção) e 2 (águas destinadas ao abastecimento doméstico, após tratamento convencional, à irrigação de hortaliças ou plantas frutíferas e à recreação de contato primário (natação, esqui-aquático e mergulho) pela 
BELÓ, A.; QUINÁIA, S. P.; OLIVEIRA, N. K.; WATZLAWICK, L. F. Caracterização de metais em precipitação atmosférica em uma Floresta Ombrófila Mista. Ambi-Agua, Taubaté, v. 4, n. 2, p. 200-211, 2009. (doi:10.4136/ambi-agua.98)

Resolução do CONAMA (Brasil, 2008) e o limite de detecção para cada metal avaliado pela técnica de FAAS. O LD representa a menor concentração do analito que pode ser detectada e qualquer valor abaixo do LD do método não deve ser expresso porque este não possui precisão e exatidão (Mendham et al., 1989). O LD do equipamento (em concentração) para cada um dos metais foi considerado igual a três vezes o desvio padrão do branco. Dentre os elementos estudados, os valores encontrados para o $\mathrm{Cd}$, nas amostras de fração dissolvida, foram inferiores ao limite de detecção (LD).

Tabela 3. Teores mínimos e máximos de metais encontrados em amostras de material particulado de águas de mina (M), precipitação dentro da floresta (D) e precipitação fora da floresta (F).

\begin{tabular}{cccc}
\hline \multicolumn{4}{c}{ Amostras de material particulado } \\
\hline Parâmetros & M & D & F \\
$\mathrm{Al}(\mathrm{mg} / \mathrm{L})$ & $38,98-4.162,50$ & $38,16-4.700,00$ & $30,67-5.200,00$ \\
$\mathrm{Cd}(\mathrm{mg} / \mathrm{L})$ & $\mathrm{LD}-6,25$ & $\mathrm{LD}-8,33$ & $\mathrm{LD}-2,50$ \\
$\mathrm{Cr}(\mathrm{mg} / \mathrm{L})$ & $\mathrm{LD}-3,50$ & $\mathrm{LD}-7,25$ & $\mathrm{LD}-1,50$ \\
$\mathrm{Fe}(\mathrm{mg} / \mathrm{L})$ & $\mathrm{LD}-419,17$ & $\mathrm{LD}-79,00$ & $3,13-55,75$ \\
$\mathrm{Mn}(\mathrm{mg} / \mathrm{L})$ & $\mathrm{LD}-14,00$ & $\mathrm{LD}-100,00$ & $\mathrm{LD}-44,86$ \\
$\mathrm{Ni}(\mathrm{mg} / \mathrm{L})$ & $\mathrm{LD}-12,50$ & $\mathrm{LD}-20,00$ & $\mathrm{LD}-11,00$ \\
$\mathrm{~Pb}(\mathrm{mg} / \mathrm{L})$ & $\mathrm{LD}-35,00$ & $\mathrm{LD}-41,25$ & $\mathrm{LD}-47,50$ \\
\hline
\end{tabular}

LD = Limite de detecção.

Tabela 4. Limite de detecção calculado a partir do desvio padrão da curva analítica e limite estabelecido pelo CONAMA no 357 , para Classe 1 e 2 - Águas Doces.

\begin{tabular}{ccc}
\hline Metais & Limite de detecção $\left(\mathbf{m g . L}^{\mathbf{- 1}}\right)$ & Limite CONAMA $\left(\mathbf{m g} . \mathbf{L}^{\mathbf{- 1}}\right)$ \\
\hline $\mathrm{Al}(\mathrm{mg} / \mathrm{L})$ & 0,169 & 0,100 \\
$\mathrm{Cd}(\mathrm{mg} / \mathrm{L})$ & 0,093 & 0,001 \\
$\mathrm{Cr}(\mathrm{mg} / \mathrm{L})$ & 0,018 & 0,050 \\
$\mathrm{Fe}(\mathrm{mg} / \mathrm{L})$ & 0,025 & 0,300 \\
$\mathrm{Mn}(\mathrm{mg} / \mathrm{L})$ & 0,041 & 0,100 \\
$\mathrm{Ni}(\mathrm{mg} / \mathrm{L})$ & 0,101 & 0,025 \\
$\mathrm{~Pb}(\mathrm{mg} / \mathrm{L})$ & 0,096 & 0,010 \\
\hline
\end{tabular}

Como a quantidade de resultados obtidos em todas as análises foi elevada, aplicou-se uma ferramenta estatística para a elucidação do diagnóstico final. A análise de componentes principais (ACP) permite a visualização e redução de dados contidos em tabelas de grandes dimensões, cruzando certo número de indivíduos com as variáveis quantitativas que os caracterizam com maior facilidade de interpretação (Pardo et al., 2004). A análise dos componentes principais foi aplicada aos resultados experimentais para verificar as semelhanças e diferenças entre as amostras e a correlação entre as variáveis. O princípio dessa análise é transformar o conjunto original de variáveis em um conjunto menor de combinações lineares, que responda pela maior parte da variância do conjunto original, de modo que as variáveis com características semelhantes possam ser agrupadas em fatores. A ACP, efetuada por meio do programa Statistica versão 6.0, foi realizada a partir de dados normalizados. Um conjunto de dados com 7 variáveis e 136 amostras foi formado para a fração dissolvida. Para a elaboração da ACP foram descartadas as variáveis $\mathrm{pH}$ e $\mathrm{Cr}$ devido a esses fatores não apresentarem variação significativa entre os pontos coletados, conforme pode ser verificado na Tabela 1. O conjunto de dados formado para o material particulado foi de 7 variáveis e 52 amostras.

O estudo quimiométrico foi dividido em duas partes, a primeira parte envolvendo a análise de componentes principais dos resultados obtidos com as amostras da fração dissolvida 
BELÓ, A.; QUINÁIA, S. P.; OLIVEIRA, N. K.; WATZLAWICK, L. F. Caracterização de metais em precipitação atmosférica em uma Floresta Ombrófila Mista. Ambi-Agua, Taubaté, v. 4, n. 2, p. 200-211, 2009. (doi:10.4136/ambi-agua.98)

(Figuras 3 e 4) e a segunda análise foi orientada aos resultados obtidos para as amostras do material particulado (Figuras 5 e 6).

Para a fração dissolvida, a primeira e segunda componentes principais capturaram juntas 50,74\% de variância dos dados experimentais. Em 33,80\% de variância capturada pela primeira componente principal (eixo $\mathrm{x}$ ), as amostras foram divididas em grupos. Houve a formação de um grupo envolvendo as amostras da coleta 7 (eixo negativo de $\mathrm{x}$ ), relativa ao mês de janeiro de 2007, em que essa amostragem caracterizou-se por altos valores de concentrações de metais ( $\mathrm{Mn}, \mathrm{Al}$ e $\mathrm{Ni}$ ) e baixo $\mathrm{pH}$ devido a uma estiagem ocorrida nesse período. Outro grande grupo foi formado próximo ao eixo central reunindo todas as amostras da demais coletas, no entanto as amostras das coletas 2,8, 9, 10 e 11 apresentaram maiores scores e se distanciaram mais do ponto central, tornando-os um pouco mais distintos em relação aos demais. A ACP separou as amostras em função da data de coleta e não em relação aos pontos M, D e F (Figura 4), o que caracteriza que o teor de metais na precipitação depende fortemente do clima (ventos, chuva e estiagem). Os diversos poluentes atmosféricos gerados por atividades antrópicas sofrem dispersão com os ventos atingindo áreas onde a geração desses poluentes é muito baixa, provocando o repasse deles por deposição seca ou pela precipitação (Roorda-Knape et al., 1998). Correlacionando-se as amostras com as variáveis foi possível verificar que as amostras das coletas 7, 8, 10 e 11 se separam das demais devido às variáveis $\mathrm{Ni}, \mathrm{Mn}$ e $\mathrm{Al}$ (eixo negativo de $\mathrm{x}$ ) e as demais coletas pelas variáveis condutividade, $\mathrm{Pb}$ e $\mathrm{Fe}$ (eixo positivo de $\mathrm{x}$ ). Ainda pode ser observado que as amostras presentes no quadrante positivo y (PC2) estão agrupando as amostras M (água de nascente) e $\mathrm{D}$ (precipitação coletada no interior da floresta) com a condutividade, enquanto as amostras $\mathrm{F}$ (precipitação coletada fora do perímetro florestal) estão localizadas no quadrante negativo de $\mathrm{y}$, indicando que as amostras coletadas nesse ponto são inversamente proporcionais aos pontos M e D.

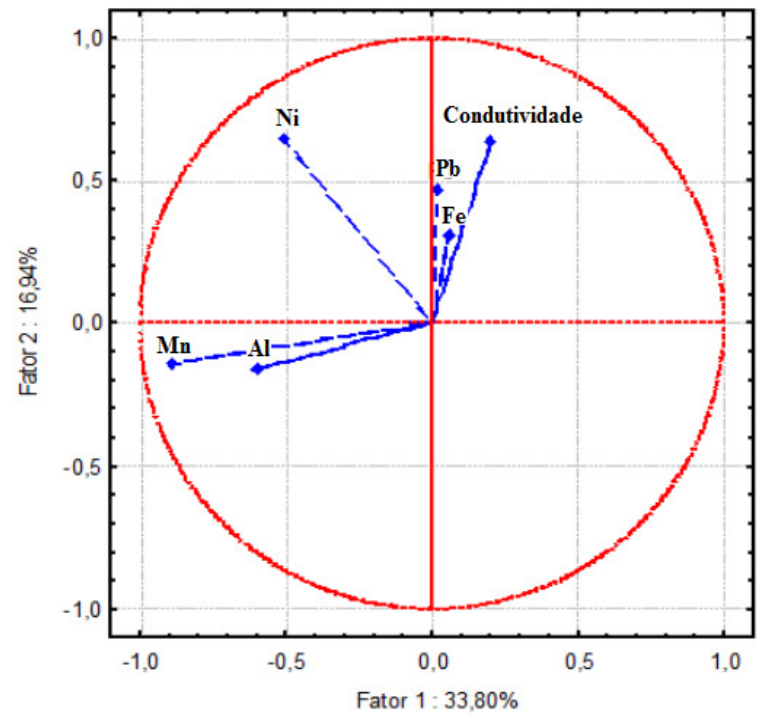

Figura 3. Gráfico de loadings para amostras da fração dissolvida. 
BELÓ, A.; QUINÁIA, S. P.; OLIVEIRA, N. K.; WATZLAWICK, L. F. Caracterização de metais em precipitação atmosférica em uma Floresta Ombrófila Mista. Ambi-Agua, Taubaté, v. 4, n. 2, p. 200-211, 2009. (doi:10.4136/ambi-agua.98)

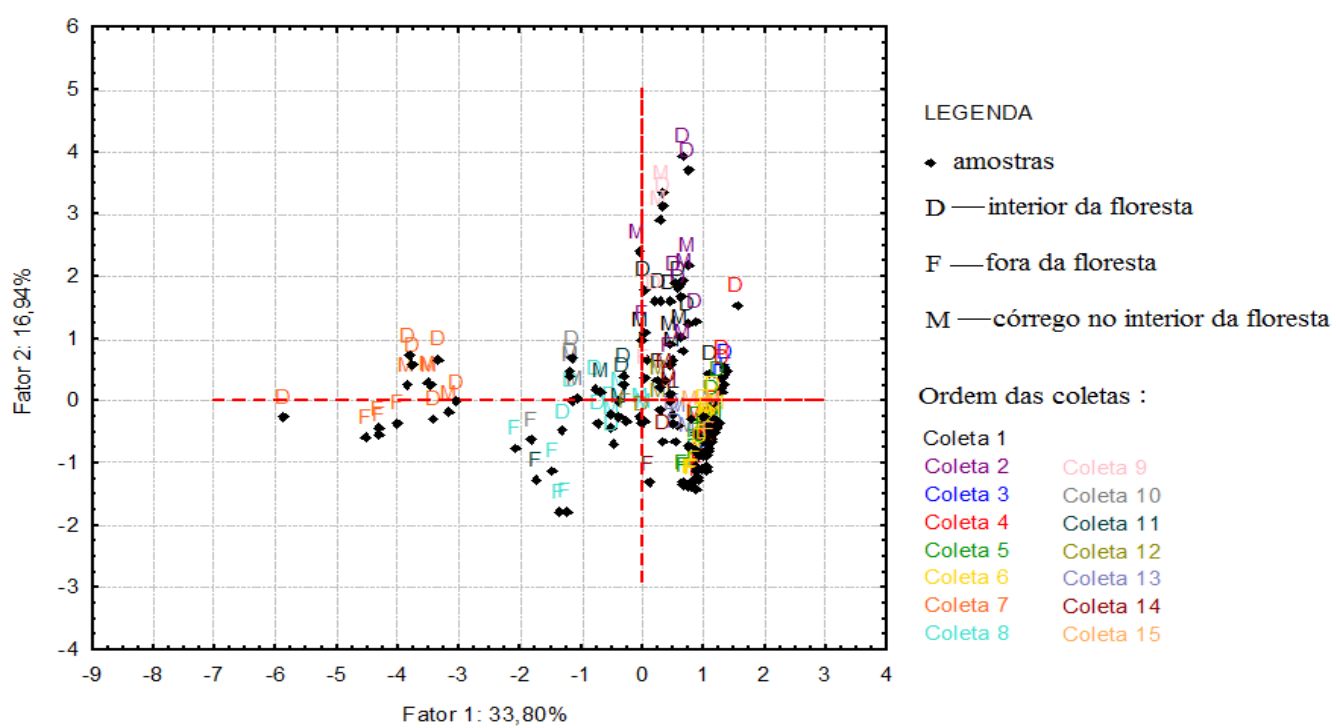

Figura 4. Gráfico de scores para amostras da fração dissolvida (água de mina (M), água de precipitação dentro da floresta (D) e precipitação fora da floresta (F).

Para as amostras de material particulado, o fator 1 explicou $51,48 \%$, enquanto o fator 2 explicou $25,02 \%$ de variância dos dados experimentais. Nesses fatores encontram-se dois grupos e algumas amostras espalhadas conforme a data da coleta (coleta $7 \mathrm{em}$ janeiro e coleta 11 em de abril/2007). A coleta 7 relacionou-se com as variáveis $\mathrm{Mn}, \mathrm{Cd}$ e $\mathrm{Ni}$, enquanto a coleta 11 relacionou-se com as variáveis $\mathrm{Al}, \mathrm{Cr}, \mathrm{Fe}$ e $\mathrm{Pb}$. As amostras que ficaram no quadrante positivo de x não apresentaram teores significativos dos metais estudados.

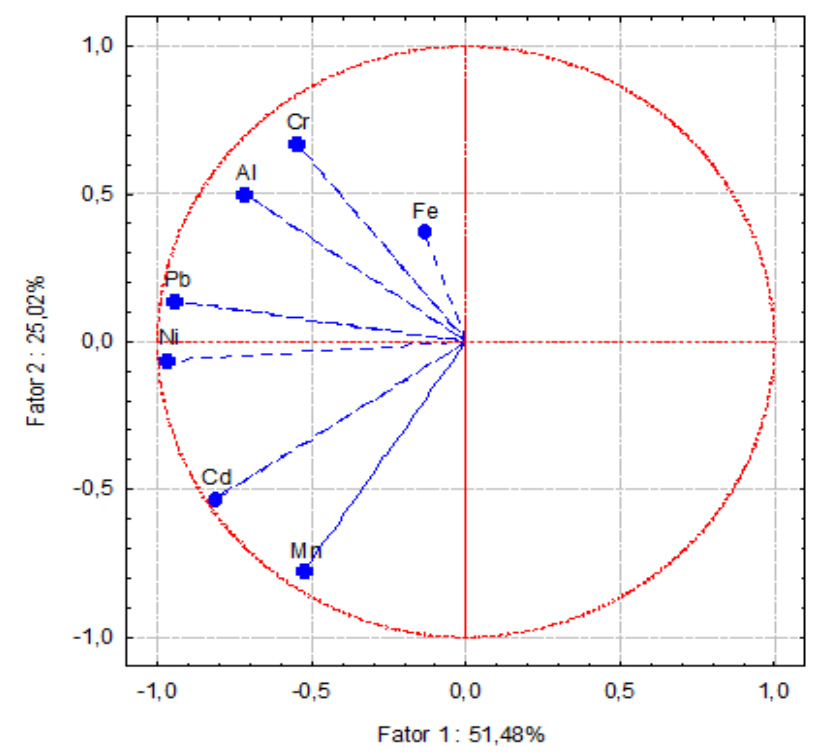

Figura 5. Gráfico de loadings para o material particulado. 
BELÓ, A.; QUINÁIA, S. P.; OLIVEIRA, N. K.; WATZLAWICK, L. F. Caracterização de metais em precipitação atmosférica em uma Floresta Ombrófila Mista. Ambi-Agua, Taubaté, v. 4, n. 2, p. 200-211, 2009. (doi:10.4136/ambi-agua.98)

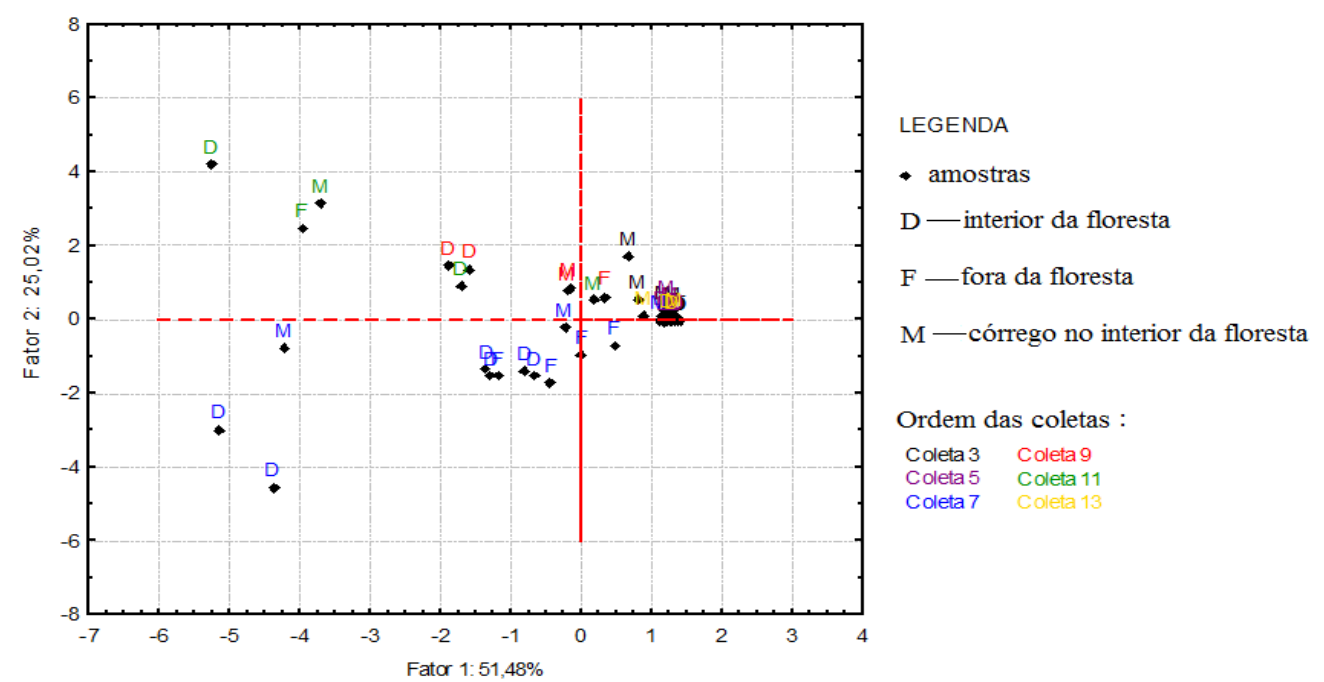

Figura 6. Gráfico de scores para o material particulado (água de mina (M), água de precipitação dentro da floresta (D) e precipitação fora da floresta (F).

\section{CONCLUSÕES}

Os resultados de $\mathrm{pH}$ da precipitação atmosférica na região de Guarapuava revelaram a ocorrência de precipitação levemente ácida. Amostras coletadas dentro da floresta obtiveram valores de $\mathrm{pH}$ maiores, devido ao material particulado depositado na superfície das plantas contribuirem com a alteração do $\mathrm{pH}$ da precipitação que cai sobre o solo da floresta. Metais tóxicos de origem antropogênica foram encontrados, demonstrando que os fenômenos climáticos contribuem na dispersão da poluição provenientes do meio urbano. Como o número de amostras e variáveis medidas foi grande, o emprego da Análise Multivariada ACP, permitiu correlacionar com maior facilidade os valores de condutividade e os teores de metais para a precipitação atmosférica e seu material particulado. As características de cada evento chuvoso (intervalo de tempo entre as precipitações atmosféricas; duração e intensidade) foram responsáveis pela discriminação das amostras provenientes de cada coleta e também entre os pontos dentro da floresta em relação àquelas pertencentes aos pontos fora da floresta e a nascente de água (ponto de referência). Os resultados obtidos podem ser utilizados para o estudo de previsão ou classificação das águas que caem sobre o solo de uma floresta diferentemente das águas que caem sobre um solo com pouca cobertura vegetal.

\section{REFERÊNCIAS}

BAIRD, C. Química Ambiental. Tradução: Maria Angeles Lobo Recio e Luiz Carlos Marques Carrera. 2. ed. Porto Alegre: Bookman, 2002.

BRASIL. Ministério do Meio Ambiente. Conselho Nacional do Meio Ambiente - CONAMA. 2005. Resolução Conama $\mathbf{n}^{\mathbf{0}}$ 357. Disponível em: < www.mma.conama.gov.br/conama>. Acesso em: nov de 2008.

CAMPOS, V. P.; COSTA, A. C. A.; TAVARES T. M. Comparação de dois tipos de amostragem de chuva: deposição total e deposição apenas úmida em área costeira tropical. Química Nova, São Paulo, v. 21, n. 4, p. 418-423, 1998.

FONTENELE, A. P. G.; PEDROTTI, J. J. Avaliação de metais traços e íons majoritários em águas de chuva na cidade de São Paulo. Química Nova, São Paulo, v. 32, n. 4, p. 839844, 2009. 
BELÓ, A.; QUINÁIA, S. P.; OLIVEIRA, N. K.; WATZLAWICK, L. F. Caracterização de metais em precipitação atmosférica em uma Floresta Ombrófila Mista. Ambi-Agua, Taubaté, v. 4, n. 2, p. 200-211, 2009. (doi:10.4136/ambi-agua.98)

GOOGLE MAPS BRASIL. 2009. Disponível em: http://maps.google.com.br. Acesso em: jul. 2009.

INSTITUTO BRASILEIRO DE GEOGRAFIA E ESTATÍSTICA - IBGE. Manual técnico da vegetação brasileira. Rio de Janeiro: IBGE, 1992 (Série Manuais Técnicos em Geociências, 1).

JARDIM, G. M.; ARMAS, E. D.; MONTEIRO, R. T. R. Ecotoxicological assessment of water and sediment of the Corumbataí River, SP, Brazil. Brazilian Journal of Biology, São Carlos, v. 68, n. 1, p. 51-59, 2008.

JESUS, E. F. R. A importância do estudo das chuvas ácidas no contexto da abordagem climatológica. Sitientibus, Feira de Santana, n. 14, p. 143-153, 1996.

KLEIN, R. M. O aspecto dinâmico do pinheiro brasileiro. Sellowia, Itajaí, v. 12, n. 12, p. 1744,1960

LARINI, L. Toxicologia. 3. ed.. São Paulo: Manole, 1997. 300 p.

LEE, J. D. Química inorgânica não tão concisa. Trad. da 4. ed. inglesa. São Paulo: Edgard Blücher, 1996. 527 p.

LOUREIRO, L. N. Panorâmica sobre emissões atmosféricas, estudo de Caso: avaliação do inventario de emissões atmosféricas da região metropolitana do Rio de Janeiro para fontes móveis. 2005. Dissertação (Mestrado em Planejamento Energético) Universidade Estadual do Rio de Janeiro, Rio de Janeiro, 2005.

MARIANI, C. F. Reservatório Rio Grande: caracterização limnológica da água e biodisponibilidade de metais-traço no sedimento. 2006. Dissertação (Mestrado em Ecologia: Ecossistemas Terrestres e Aquáticos) - Universidade de São Paulo, São Paulo, 2006.

MENDHAM, J.; DENNEY, R. C.; BARNES, J. D.; THOMAS, M. J. K. VOGEL: análise química quantitativa. Tradução: Afonso, J. C. et al. 5. ed. Rio de Janeiro: Guanabara Koogan, 1989. 665 p.

MIGLIAVACCA, D. M.; TEIXEIRA, E. C.; MACHADO, A. C.; PIRES, M. R. Composição química da precipitação atmosférica no sul do Brasil:estudo preliminar. Química Nova, São Paulo, v. 28, n. 3, p. 371-379, 2005.

PARDO, R.; HELENA, B. A.; CAZURRO, C.; GUERRA, C.; DEBÁN, L.; GUERRA, C. M.; VEGA, M. Application of two- and three-way principal component analysis to the interpretation of chemical fractionation results obtained by the use of the B.C.R. procedure. Analytica Chimica Acta, v. 523, n. 1, p. 125-132, 2004.

PIMENTEL, L. C. F.; CHAVES, C. R.; FREIRE, L. A. A.; AFONSO, J. C. O inacreditável emprego de produtos químicos perigosos no passado. Química Nova, São Paulo, v. 29, n. 5, p. 1138-1149, 2006.

PRESTES, E. C.; ANJOS, V. E.; SODRÉ, F. F.; GRASSI, M. T. Copper, lead and cadmium loads and behavior in urban stormwater runoff in Curitiba, Brazil. Journal of the Brazilian Chemical Society, São Paulo, v. 17, n. 1, p. 53-60, 2006. 
BELÓ, A.; QUINÁIA, S. P.; OLIVEIRA, N. K.; WATZLAWICK, L. F. Caracterização de metais em precipitação atmosférica em uma Floresta Ombrófila Mista. Ambi-Agua, Taubaté, v. 4, n. 2, p. 200-211, 2009. (doi:10.4136/ambi-agua.98)

ROORDA-KNAPE, M. C.; JANSSEN, N. A. H.; DE HARTOG, J.; VAN VLIET, P. H. N.; HARSSEMA, H.; BRUNEKREE, B. Air pollution from traffic in city districts near major motorways. Atmospheric Environment, Amsterdam, v. 32, n. 11, p. 1921-1930, 1998.

QUEIROZ, P. G. M.; JACOMINO, V. M. F.; MENEZES, M. A. B. C. Composição elementar do material particulado presente no aerossol atmosférico do município de Sete Lagoas, Minas Gerais. Química Nova, São Paulo, v. 30, n. 5, p.1233-1239, 2007.

SILVA, C. Caracterização da Bacia do Rio Fiúza para aplicação na prevenção de enchentes. 2006. 50f. Monografia (Graduação em Engenharia Civil) - Universidade Regional do Noroeste do Estado do Rio Grande do Sul, Ijuí, 2006.

SONEGO, R. C.; BACKES, A.; SOUZA, A. F. Descrição da estrutura de uma Floresta Ombrófila Mista, RS, Brasil, utilizando estimadores não-paramétricos de riqueza e rarefação de amostras. Acta Bor. Bras. São Paulo, v. 21, n. 4, p. 943-955, 2007.

SOUZA, V. V.; DIAS, H. C. T.; COSTA, A. A.; OLIVEIRA, J. C. Análise da qualidade das águas das precipitações em aberto e efetiva em um fragmento secundário da Mata Atlântica, no município de Viçosa, MG. Revista Árvore, Viçosa-MG, v. 31, n. 4, p. 737-743, 2007. 